\title{
Practical recommendations for the transition to adulthood for the adolescent with a genetic diagnosis. Special emphasis on inborn errors of metabolism
}

\author{
Mauricio De Castro ${ }^{\mathrm{a}, *}$, Clesson Turner ${ }^{\mathrm{b}}$ and Brian Kirmse \\ ${ }^{a}$ Air Force Medical Genetics Center, Keesler AFB, MS, USA \\ ${ }^{\mathrm{b}}$ Walter Reed Army Medical Center, Bethesda, MD, USA \\ ${ }^{\mathrm{c}}$ University Of Mississippi Medical Center, Jackson, MS, USA
}

\begin{abstract}
Taken as a group, genetic disorders affect a significant proportion of the population. Historically thought of as pediatric disorders, inborn errors of metabolism (IEM) are becoming increasingly relevant to the adult clinical provider; given the improvements in screening, diagnosis and management, an increasing number of children with IEM's are able to transition adulthood. Currently available data suggests that adult-medicine clinical providers are ill-prepared to appropriately care for this population. Although practical management and transition guidelines exist for a minority of disorders, there is a significant lack of guidance for the great majority of conditions. Based on our review of the relevant literature, we set out to provide practical recommendations to assist in the transition from adolescence to adulthood, with an emphasis on patients with an inborn error of metabolism.
\end{abstract}

Keywords: Inborn error of metabolism, transition in care, adult genetic disease

\section{The burden of genetic disease in adults}

There is an unexpected paradox when discussing the population prevalence of genetic disorders; they are rare but also common. On an individual basis, genetic diagnoses are rare. Some genetic disorders are so rare that only a handful of reported cases worldwide exist, and even the incidence of the most common genetic conditions such as familial hypercholesterolemia [1] (1 in 256) or the hereditary breast and ovarian cancer syndrome (HBOC) [2] (1 in 450) pales in comparison with common multifactorial disorders in adults such as hypertension [3] (as high as 1 in 3) or type 2 diabetes [4] (1 in 12). However, when taken together as a group, Mendelian disorders are thought to affect close to 1 in 10 individuals according to the National Organization for rare Disorders (https://rarediseases.org/). Of note, these numbers do not take into account relatively frequent but incompletely penetrant genetic disorders such as hereditary hemochromatosis and factor V Leiden.

The same holds true for inborn errors of metabolism (IEM), although individually rare, when taken together they affect 1 in 1,000 individuals [5]. Inborn errors are a group of Mendelian disorders wherein the genetic lesion is in a gene that primarily affects a unit step of metabolism. The archetypal IEM is

\footnotetext{
${ }^{*}$ Corresponding author: Mauricio De Castro, Air Force Medical Genetics Center, Keesler AFB, MS, USA. E-mail: mauricio.j.decastropretelt.mil@mail.mil.
} 
phenylketonuria (PKU), a disorder caused by phenylalanine hydroxylase deficiency that is typically identified by state-run newborn screening programs and treated for life with a combination of diet modification (protein restriction and medical formula) and pharmacologic intervention (cofactor supplementation (BH4) and enzyme replacement therapy (pegvaliase)). Historically, IEM's were thought about as pediatric conditions but they are becoming increasingly relevant in the adult population. Much of this rising interest comes as a consequence of a better understanding of the human genome and the increasing role molecular testing and genetics and genomics as a whole play in mainstream medicine.

The number of genetic tests offered by clinical laboratories has grown at a steady pace since the elucidation of the human genome in the early 2000's. There are reportedly, a staggering 75,000 genetic tests on the market with 10 new tests entering the market daily [6]. The widespread availability of genetic testing has led to the increased recognition of milder phenotypes and the discovery of the molecular etiology of many disorders [7-9], heretofore only identified or defined clinically. Case in point, the American College of Medical Genetics (ACMG) guidelines recommend that pathogenic and likely pathogenic variants in 59 clinically actionable genes, unrelated to the underlying reason for testing, be returned by clinical laboratories for clinicians to use, with appropriate consent, in their patients' care [10]; 1-3\% of individuals harbors one of these medically actionable variants [11] and up to an additional $50 \%$ of individuals are carriers for a rare disorder. It is not unusual for an ostensibly healthy adult to receive a new diagnosis of a genetic disorder after undergoing testing for an unrelated indication, and when genomic sequencing technology is employed for diagnosis, it is not uncommon to find more than one genetic disease in a patient [12].

Inborn errors of metabolism have traditionally been thought about as exclusive or primarily affecting the pediatric population, this view is partly based on the fact that severe presentations will almost invariably manifest in neonates and children. This has created a skewed population of providers caring for these patients; for example, in looking at the breakdown of primary specialty for board certified geneticists in the United States, $80 \%$ of them (as of 2018) are either pediatricians or obstetrician/gynecologists.

Although it has been recognized for some time that some IEM's have mild presentations or slowly progressive courses, the last several years have seen advances in testing and therapies, early disease recognition and a broadening understanding of genetics that has allowed for two situations to arise; 1. Increased recognition of genetic disorders presenting in adolescence or adulthood; and 2. Increased life expectancy for children with, otherwise fatal, early-onset genetic disease. The overarching result is a novel patient population not adequately addressed by the existing healthcare paradigm. Clinical providers caring for adults with IEM will not only manage patients with adult onset disorders but also adults with early-onset disorders that have been successfully managed through childhood and adolescence.

There is literature that suggests that the average healthcare provider may be underprepared to deal with the expanding genetic needs of the adult population. A 2010 study showed that in about $30 \%$ of the cases, there were problems with tests ordered, the most common being ordering the wrong test [13]. In a different study looking at self-perception of knowledge base, a full $74 \%$ of providers rated themselves at "somewhat poor" or "very poor" and close to $80 \%$ recognized their need for additional training [14]. When looking at the comfort level of pediatricians and internists in providing care for young adults with genetic disorders, a majority felt unprepared to do so and there was no clear consensus on which specialty should care for these patients [15]. An additional issue is the lack of guidelines, standards and systems in place [16] to guarantee the proper transition from adolescence to adulthood with data to suggest that young people suffer deteriorating health as they drift away from the adult health care teams $[17,18]$.

These issues highlight why, now more than ever, there needs to be a concerted effort from provider education and training, health care systems, medical insurance companies, patient-led groups 
Table 1

Examples of inborn errors of metabolism with milder adult-onset forms

\begin{tabular}{|c|c|c|c|}
\hline Disorder & Gene & Childhood presentation & Adult presentation \\
\hline Fabry disease & $G L A$ & Crisis of acroparesthesia & $\begin{array}{l}\text { Strokes, cardiomyopathy, } \\
\text { hearing loss, proteinuria }\end{array}$ \\
\hline Wilson disease & $A T P 7 B$ & Liver failure & $\begin{array}{l}\text { Dysarthria, kidney failure, psych } \\
\text { symptoms, parkinsonism }\end{array}$ \\
\hline Gaucher type 1 & $G B A$ & Bone disease, hepatomegaly & Parkinson's disease \\
\hline OTC deficiency & OTC & Coma, failure to thrive & $\begin{array}{c}\text { Protein aversion, abdominal } \\
\text { pain, stroke-like episodes }\end{array}$ \\
\hline Homocystinuria & $C B S$ & $\begin{array}{l}\text { Developmental delay, lens } \\
\text { dislocation, scoliosis }\end{array}$ & Strokes, thrombophilia \\
\hline CPT II & $C P T 2$ & Cardiomyopathy and liver failure & Rhabdomyolysis \\
\hline GM2 gangliosidosis & $H E X A$ & $\begin{array}{l}\text { Progressive neuro deterioration, } \\
\text { visual loss, cherry red spot }\end{array}$ & $\begin{array}{l}\text { Motor neuron disease, dystonia, } \\
\text { psychosis }\end{array}$ \\
\hline Adrenoleukodystrophy & $A B C D 1$ & $\begin{array}{l}\text { Early-onset dementia, ataxia, } \\
\text { quadriplegia }\end{array}$ & $\begin{array}{l}\text { Psych symptoms, chronic spastic } \\
\text { paraparesis }\end{array}$ \\
\hline Niemann-Pick type C & $N P C 1$ & $\begin{array}{l}\text { Liver disease, developmental } \\
\text { delay, vertical SNGP }\end{array}$ & Ataxia, psychosis, splenomegaly \\
\hline MSUD & DBT ВСКDHB ВCKDHA & Coma, failure to thrive & $\begin{array}{l}\text { Encephalopathy, episodes of } \\
\text { nausea and vomiting }\end{array}$ \\
\hline GAMT deficiency & $G A M T$ & $\begin{array}{l}\text { Developmental delay, hypotonia, } \\
\text { seizures }\end{array}$ & Isolated myopathy \\
\hline
\end{tabular}

*CPTII, Carnitine Palmitoyltransferase II; GAMT, Guanidinoacetate Methyltransferase; OTC, Ornithine Transcarbamylase; SNGP, Supranuclear Gaze Palsy.

and professional organizations to ensure the transition from adolescent to adult genetics care is successful.

\section{Addressing the problem}

The exact prevalence of IEM in the adult population is currently unknown. As mentioned previously, there are two main groups requiring the involvement of knowledgeable clinical providers in this population. Genetic disorders with adult-onset forms (see Table 1), and conditions that present in childhood or adolescence but either due to their slowly progressive course or effective treatment, become chronic conditions with prolonged life expectancy [19] (see Table 2). Both groups will benefit from a comprehensive and systematic approach to their care.

There is currently no agreed upon answer to the question of who assumes responsibility for the care of adult patients with IEM. Many adult-onset forms of IEM have as a cardinal feature neurological symptoms such as seizures [20], spastic paraparesis [21], peripheral neuropathy [22], movement disorders [23] (chorea, parkinsonism, tics or myoclonus) or psychosis and other atypical psychiatric manifestations [24]. By virtue of their presentation, a large percentage of adult-onset patients are seen and managed by neurologists or psychiatrists; other IEM's however can present with prominent liver failure [25] (Wilson disease, hereditary hemochromatosis, citrin deficiency); cardiac manifesations [26] (cardiomyopathy, cardiomegaly, electrical conduction disorders) or other major organ systems primarily affected, prompting evaluation and management by the respective specialist.

In the case of pediatric patients transitioning to adult care, the question is no closer to being answered conclusively. There is currently no general established guidelines as to who owns primary responsibility 
Table 2

Examples of treatable inborn errors of metabolism with increased life expectancy

\begin{tabular}{|c|c|c|}
\hline Disorder & Treatment & Residual phenotype \\
\hline Classic PKU & Dietary modifications, Kuvan ${ }^{\circledR}$ & $\begin{array}{l}\text { Mild intellectual disability, } \\
\text { neuropsychological issues }\end{array}$ \\
\hline MSUD & Dietary modifications, OLT & $\begin{array}{l}\text { Mild intellectual disability, ADHD, } \\
\text { anxiety }\end{array}$ \\
\hline MMA/PA & $\begin{array}{l}\text { Dietary modifications, carnitine, MTZ, } \\
\text { liver transplant, hydroxycobalamin }\end{array}$ & $\begin{array}{l}\text { Mild-moderate intellectual disability, } \\
\text { movement disorders, renal } \\
\text { impairment }\end{array}$ \\
\hline GSD I (von Gierke disease) & $\begin{array}{l}\text { Dietary modifications, liver/kidney } \\
\text { transplant }\end{array}$ & $\begin{array}{l}\text { Renal impairment, hepatic adenomas, } \\
\text { osteoporosis, anemia }\end{array}$ \\
\hline Classic galactosemia & Dietary modifications & $\begin{array}{l}\text { Growth retardation, cognitive delays, } \\
\text { movement disorders, osteoporosis }\end{array}$ \\
\hline MCAD deficiency & Dietary modifications & $\begin{array}{l}\text { Case reports of pregnancy-related } \\
\text { complications (hypoglycemia, acute } \\
\text { liver failure) }\end{array}$ \\
\hline Tyrosinemia type I & $\begin{array}{l}\text { Dietary modifications, Nitisinone, liver } \\
\text { transplant }\end{array}$ & Intellectual disability, liver cancer \\
\hline Holocarboxylase Synthetase deficiency & Biotin supplementation & Intellectual disability \\
\hline Mucopolysaccharidosis type II & Enzyme replacement therapy, HSCT & Residual neurological disease \\
\hline
\end{tabular}

*HSCT, Hematopoietic Stem Cell Transplantation; GSD, Glycogen Storage Disease; MCAD, Medium-Chain AcylCoenzyme A Dehydrogenase; MMA, Methylmalonic Acidemia; MSUD, Maple Syrup Urine Disease; MTZ, Metronidazole; OLT, Orthotopic Liver Transplantation; PA, Propionic Acidemia; PKU, Phenylketonuria.

for these patients [15]; in the case of more common genetic disorders such as cystic fibrosis, much work has been done to develop bona-fide adult programs, modeled after pediatric programs, and ensuring the collaboration between pediatric and adult counterparts. The results are the establishment of successful transition programs ensuring lifelong appropriate treatment and improved outcomes [27]. Programs such as these or those that have been developed for congenital heart disease [28] or even non-genetic disorders like pediatric HIV infection [29], can be looked to as models or templates for the myriad genetic disorders that are expected to need coordinated efforts to transition patients into adult care. For the majority of genetic disorders however, it varies between centers, with some of these patients still being followed by the pediatrics department to some extent while others have made the transition to internal medicine, family practice or other adult medicine departments.

Studies looking at centers specialized in the care of adults with IEM in Europe show that the most common diagnoses are conditions for which there is treatment in the form of replacement therapy or dietary modifications such as disorders of amino acid metabolism, lysosomal storage disorders, mitochondrial disorders and glycogen storage disorders [30] (see Table 3). The age of diagnosis is quite variable, as expected. Conditions such as PKU are overwhelmingly (84\%) diagnosed at the newborn stage while others such as mitochondrial disorders $(85 \%)$, Fabry disease and homocystinuria are diagnosed in adulthood [31]. In a large cohort of 2,022 patients seen at centers specializing in the care of adults with IEM, a significant proportion of cases (45.7\%) were diagnosed in adulthood [31], of particular interest are conditions that could present initially as a metabolic crisis in adulthood such as ornithine transcarbamylase (OTC) deficiency, or the porphyrias in which as many as 50-90\% of cases presented in adulthood. These data support the importance of having competent, well-trained adult providers ready to take on this growing population and a good starting point to identify conditions to 
Table 3

Common inborn errors of metabolism observed in a large cohort of patients seen in specialized adult centers in Europe

\begin{tabular}{lcc}
\hline Disorder & Median Age & Percentage of the total \\
\hline PKU & 34 & $20 \%$ \\
Fabry disease & 45 & $8.8 \%$ \\
CPEO & 59.5 & $4.3 \%$ \\
Gaucher disease & 48 & $4.2 \%$ \\
Homocystinuria & 35 & $3.9 \%$ \\
X-adrenoleukodystrophy & 47 & $3.8 \%$ \\
Pompe disease & 55 & $3.6 \%$ \\
Galactosemia & 29 & $2.7 \%$ \\
MELAS & 42 & $2.6 \%$ \\
Trimethylaminuria & 44 & $2.4 \%$ \\
McArdle disease & 51 & $2.5 \%$ \\
OTC deficiency & 33 & $2.2 \%$ \\
Hypophosphatemic rickets & 36 & $1.4 \%$ \\
Maple syrup urine disease & 27 & $1.1 \%$ \\
GSD III (Cori disease) & 38 & $1 \%$ \\
GSD I (von Gierke disease) & 29 & $1 \%$ \\
Niemann-Pick type C & 35 & $0.9 \%$ \\
MCAD deficiency & 23 & $0.8 \%$ \\
\hline
\end{tabular}

*CPEO, Chronic Progressive External Ophthalmoplegia; GSD, Glycogen Storage Disease; MCAD, Medium-Chain Acyl-Coenzyme A Dehydrogenase; MELAS, Mitochondrial Encephalopathy, Lactic Acidosis and Stroke-Like Episodes; OTC, Ornithine Transcarbamylase; PKU, Phenylketonuria.

be prioritized in terms of medical management guideline development and educational interventions for physicians and other providers.

\section{Practical recommendations}

It is important to recognize that the transition from adolescence to adult care carries many variables with no one-size-fit-all approach. Although the following are intended to guide the transition process from pediatric to adult care, they can also be used to guide the care of patients initially diagnosed in adulthood.

There are many medical, societal, legal and ethical issues surrounding the care of transitioning and adult IEM patients [32]. For instance, patients located in countries with highly specialized medical centers with dedicated units for adults with IEM's will have access to additional resources compared to patients living in developing countries or living in remote or rural areas. Other important issues such as medical insurance coverage, social support network, financial resources, cultural and religious barriers, age of consent and legal requirements to be an adult need to be considered for each individual.

The following guidelines are based on our personal experience with an expansive, multicenter, integrated health care system and a careful review of the literature. Although there are many guidelines that can assist with guiding the transition to care, the individual needs of the patient need be considered [30, 33-36] and should take into account the many medical, psychosocial, educational and vocational needs of the patients. 
1. Coordination of care. The care of patients with complex genetic disorders or IEM's typically requires a multidisciplinary team approach. Whenever possible, patients with an IEM should be initially evaluated at a reference academic center with ample experience and resources. Once the patient has had a thorough evaluation and a comprehensive medical management plan has been developed, continuation of care with the local provider should be established. Ideally, an interested and motivated named provider or provider group exists in the local community able to care for these patients such as described in the concept of the "medical home" promulgated by the American Academy of Pediatrics for the care of pediatric patients with complex medical needs [37].

Cooperation and clear communication between the larger academic center and local providers is paramount; this is particularly true if there are new symptoms or decompensations the local team does not feel prepared to deal with. Since this model may not be feasible in certain situations (remote location, financial limitations, difficulty with mobility/traveling), every effort should be made to seek alternative health delivery models such as home visits or telemedicine to care for these patients since the likelihood to be lost to follow up is high. Evidence suggests that having a named transition coordinator to assist in the process of navigating the health care system leads to improved outcomes [38]. Every effort should be made to designate a transition coordinator for all adult IEM patients. It is equally important that the local care team be able to provide routine adult primary care, including preventive services, counseling and age appropriate screenings for relevant adult-onset disorders such as hypertensive disease, diabetes and colon cancer.

2. Medical records and ensuring continuity of care. Patients should be encouraged to keep copies of their medical records. This is especially true when confronted with multiple referrals and studies over many years, sometimes across different provider groups, hospitals or health systems, a common occurrence for patients with IEM. These transitions in care between different systems that may not be interfaced makes the tracking of critical medical information,difficult. This is of particular importance in patients receiving multiple uncommon medications, enzyme replacement therapy or following stringent dietary modifications.

3. Active participation in care. In patients with the mental capacity to do so, the focus should be on encouraging the patient to be their own best advocate. This step involves the transition from being a passive observant to an active participant in the medical decision-making process. The patient should be educated on and learn about their specific diagnosis as much as possible. In addition to potentially improving outcomes such as increased adherence to treatment [17], this will help mitigate gaps in treatment, even when encountering providers not familiar with the specific disorder. To this end, patients and families should be provided with a layperson-friendly disease information pamphlet, contact information for patient support groups and information on educational resources on the Internet. Government-sponsored resources such as the Genetics Home Reference [39] (https://ghr.nlm.nih.gov/), patient advocacy groups (https://rarediseases.org/) or well-organized disease specific support groups such as PKU (https://npkua.org/) have valuable educational resources available to patients and their families; these can provide important information not just on the scientific aspects of the disease but also on everyday quality of life issues and allow for networking between patients and families.

Over the last decade, the rise of social media has allowed families around the world to connect with each other and form support groups for very rare disorders. These platforms allow for networking, crowdfunding [40], fundraising and the sharing of information [41]. Some of the more uncommon disorders may not have this type of readily available information but with some modification from the published literature, information can be provided to the family.

4. Provider education is paramount to any system-wide effort to improve access to care and outcomes for adolescents transitioning to adult care. Efforts should be made to target graduate medical 
education (GME) and continuing medical education (CME) initiatives for physicians and other providers. Efforts should be focused on conditions known to be more common in these patient populations (Table 3).

5. System support. Individuals and families may need assistance with the psychosocial aspects of the transition process; this is particularly true in individuals who may have intellectual or physical disabilities. Every effort should be made to ensure a smooth transition of ancillary services if still required such as speech therapy, occupational therapy, orthotics, physical therapy or psychiatric support. Appropriate support has been shown to increase medication adherence, an issue that affects a significant proportion of adolescent patients transitioning to adult care [33].

6. Autonomy and quality of life. Patients with IEM's transitioning to adulthood still need to make decisions affecting their everyday lives such as sexual activity and contraception, stress management, attending higher education, vocational issues, and substance abuse. There are specific considerations depending on the individual circumstances that need to be addressed. Effort should be made at the local level to provide education and support on these issues early on as comprehensively as possible.

It is generally assumed that patients over 18 years are legally adults (in most states) and able to make their own decisions. Although many adult patients with an IEM will retain their ability to make decisions about their life and healthcare, in individuals that are physically or mentally unable to care for themselves, courts may appoint a guardian to make decisions for the patient. The purpose of guardianship is to protect the individual's interests and rights. In some cases, guardians make decisions regarding medical treatment and end-of-life decisions. The medical team should encourage the family to seek information regarding guardianship, advance directives, medical proxies and related issues during the transition to adulthood.

\section{Additional concerns surrounding a genetic diagnosis in adolescents transitioning to adulthood}

There are some additional concerns that merit special mention for individual patients and their families in this population.

1. Transition to life after secondary school. Adolescents transitioning to adulthood have to make decisions regarding higher educational and vocational career paths. This is an area where support groups can have a positive effect; studies have shown that adolescents with chronic conditions benefit from the opportunity to exchange ideas and information with peers related to vocational or educational issues [42].

2. Economic issues. Financing long-term care of an adult with a genetic disorder. According to data from the U.S. Department of Agriculture, the average cost of raising a child in the United States over 18 years is $\$ 240,000$ [43]. Cost analysis performed in families caring for children with special needs show that this amount can be significantly higher in this population [44]. This is due not only to the direct costs associated with the increased utilization of healthcare resources used, but also other additional factors such as the need for continuous and experienced childcare/caregiving needs, parental emotional distress, and in some cases, loss of parental productivity [45-48]. Many IEM's will require continued treatment throughout adulthood, some in the form of dietary intervention (PKU) or readily available and relatively inexpensive medications/therapy (biotinidase deficiency), while others such as storage disorders requiring enzyme replacement therapy can cost hundreds of thousand of dollars per year [49]. 
3. Discrimination. Adult patients may face potential discrimination or retaliation based on their genetic information. In the United States, patients are to some extent, protected by the law. Signed by President George W. Bush in 2008, the Genetic Information Nondiscrimination Act (GINA) makes it illegal for health insurers to use genetic information to make eligibility, coverage, underwriting or premium-setting decisions. The law goes even further and states that it is illegal for insurers to request results of genetic testing or provide genetic information. Similarly, GINA makes it illegal for employers to use genetic information in employment decisions such as hiring, promotions, pay and job assignments. It is important to note that GINA does not apply to employers with fewer than 15 employees, the Veterans Health (VA) administration or the military. GINA does not cover long-term, disability or life insurance. In the United States, additional protections under the Americans with Disabilities (ADA) act may apply to adults diagnosed with an inborn error of metabolism.

4. Pregnancy. Historically, pregnancy has been a relative contraindication in patients diagnosed with an IEM. Over the last two decades, there has been an increasing number of reports of successful pregnancy outcomes in a variety of diagnoses; this presents a two-fold challenge to the treating clinician: 1. Given the significant biological stresses of pregnancy, the potential for metabolic decompensation is increased during this period of time; and 2. The consequences of the accumulation of toxic metabolites that cross the placental barrier on the growing fetus. A notable example of the first point is the urea cycle disorders. Studies performed in the 1990's showed that previously undiagnosed, asymptomatic females were posthumously diagnosed with OTC deficiency in cases of post-partum coma and death. On the other hand, an example where the main impact is on the fetus is PKU; poorly controlled phenylalanine levels in the mother are linked to worse outcomes in the fetus (maternal PKU syndrome).

5. Family planning. Because the great majority of inborn errors of metabolism are autosomal recessive or X-linked conditions, all affected patients are at risk to have an affected child. The specific risk will depend on the condition, gender of the fetus (for X-linked disorders), partner's family history and ethnicity and population carrier estimates. Genetic counseling and when indicated, testing, is strongly recommended for all adult patients with an IEM. Many alternatives exist for patients that want to have children including pre-implantation genetic diagnosis, adoption and use of a surrogate.

\section{References}

[1] N.S. Abul-Husn, K. Manickam, L.K. Jones, E.A. Wright, D.N. Hartzel, C. Gonzaga-Jauregui, C. O’Dushlaine, J.B. Leader, H. Lester Kirchner, D.M. Lindbuchler and others. Genetic identification of familial hypercholesterolemia within a single U.S. health care system, Science 354(6319) 2016.

[2] A.S. Whittemore, G. Gong, E.M. John, V. McGuire, F.P. Li, K.L. Ostrow, R. Dicioccio, A. Felberg and D.W. West, Prevalence of BRCA1 mutation carriers among U.S. non-Hispanic Whites, Cancer Epidemiol Biomarkers Prev 13(12) (2004), 2078-2083.

[3] S.S. Yoon, M.D. Carroll and C.D. Fryar, Hypertension Prevalence and Control Among Adults: United States, 20112014, NCHS Data Brief 2015(220) 1-8.

[4] K.M. Bullard, C.C. Cowie, S.E. Lessem, S.H. Saydah, A. Menke, L.S. Geiss, T.J. Orchard and D.B. Rolka, Imperatore G. Prevalence of Diagnosed Diabetes in Adults by Diabetes Type - United States, 2016, MMWR Morb Mortal Wkly Rep 67(12) (2018), 359-361.

[5] C.J. Hendriksz, Inborn errors of metabolism for the diagnostic radiologist, Pediatr Radiol 39(3) (2009), 211-220.

[6] K.A. Phillips, P.A. Deverka, G.W. Hooker and M.P. Douglas, Genetic Test Availability And Spending: Where Are We Now? Where Are We Going? Health Aff (Millwood) 37(5) (2018), 710-716.

[7] S.B. Ng, E.H. Turner, P.D. Robertson, S.D. Flygare, A.W. Bigham, C. Lee, T. Shaffer, M. Wong, A. Bhattacharjee, E.E. Eichler and others. Targeted capture and massively parallel sequencing of 12 human exomes, Nature 461(7261) (2009), 272-276. 
[8] S.B. Ng, K.J. Buckingham, C. Lee, A.W. Bigham, H.K. Tabor, K.M. Dent, C.D. Huff, P.T. Shannon and E.W. Jabs, D.A. Nickerson and others. Exome sequencing identifies the cause of a mendelian disorder, Nat Genet 42(1) (2010), 30-35.

[9] S.B. Ng, A.W. Bigham, K.J. Buckingham, M.C. Hannibal, M.J. McMillin, H.I. Gildersleeve, A.E. Beck, H.K. Tabor and G.M. Cooper, Mefford HC and others. Exome sequencing identifies MLL2 mutations as a cause of Kabuki syndrome, Nat Genet 42(9) (2010), 790-793.

[10] S.S. Kalia, K. Adelman, S.J. Bale, W.K. Chung, C. Eng, J.P. Evans, G.E. Herman, S.B. Hufnagel, T.E. Klein, B.R. Korf and others. Recommendations for reporting of secondary findings in clinical exome and genome sequencing, 2016 update (ACMG SF v2.0): A policy statement of the American College of Medical Genetics and Genomics, Genet Med 19(2) (2017), 249-255.

[11] L.M. Amendola, M.O. Dorschner, P.D. Robertson, J.S. Salama, R. Hart, B.H. Shirts, M.L. Murray, M.J. Tokita, C.J. Gallego, D.S. Kim and others. Actionable exomic incidental findings in 6503 participants: Challenges of variant classification, Genome Res 25(3) (2015), 305-315.

[12] Y. Yang, D.M. Muzny, J.G. Reid, M.N. Bainbridge, A. Willis, P.A. Ward, A. Braxton, J. Beuten, F. Xia, Z. Niu and others. Clinical whole-exome sequencing for the diagnosis of mendelian disorders, N Engl J Med 369(16) (2013), 1502-1511.

[13] R.L. Haspel and J.E. Saffitz, Genomic oncology education: An urgent need, a new approach, Cancer J 20(1) (2014), 91-95.

[14] R. Klitzman, W. Chung, K. Marder, A. Shanmugham, L.J. Chin, M. Stark, C.S. Leu and P.S. Appelbaum, Attitudes and practices among internists concerning genetic testing, J Genet Couns 22(1) (2013), 90-100.

[15] M.J. Okumura, M. Heisler, M.M. Davis, M.D. Cabana, S. Demonner and E.A. Kerr, Comfort of general internists and general pediatricians in providing care for young adults with chronic illnesses of childhood, J Gen Intern Med 23(10) (2008), 1621-1627.

[16] J. Bhawra, A. Toulany, E. Cohen, C. Moore Hepburn and A. Guttmann, Primary care interventions to improve transition of youth with chronic health conditions from paediatric to adult healthcare: A systematic review, BMJ Open 6(5) (2016), $\mathrm{e} 011871$.

[17] H. Gleeson, S. McCartney and V. Lidstone, 'Everybody's business': Transition and the role of adult physicians, Clin Med (Lond) 12(6) (2012), 561-566.

[18] M.A. McManus, L.R. Pollack, W.C. Cooley, J.W. McAllister, D. Lotstein, B. Strickland and M.Y. Mann, Current status of transition preparation among youth with special needs in the United States, Pediatrics 131(6) (2013), 1090-1097.

[19] P. Kruszka and D. Regier, Inborn Errors of Metabolism: From Preconception to Adulthood, Am Fam Physician 99(1) (2019), 25-32.

[20] S. Sharma and A.N. Prasad, Inborn Errors of Metabolism and Epilepsy: Current Understanding, Diagnosis, and Treatment Approaches, Int J Mol Sci 18(7) 2017.

[21] F. Sedel, B. Fontaine, J.M. Saudubray and O. Lyon-Caen, Hereditary spastic paraparesis in adults associated with inborn errors of metabolism: A diagnostic approach, J Inherit Metab Dis 30(6) (2007), 855-864.

[22] F. Sedel, C. Barnerias, O. Dubourg, I. Desguerres, O. Lyon-Caen and J.M. Saudubray, Peripheral neuropathy and inborn errors of metabolism in adults, J Inherit Metab Dis 30(5) (2007), 642-653.

[23] F. Sedel, J.M. Saudubray, E. Roze, Y. Agid and M. Vidailhet, Movement disorders and inborn errors of metabolism in adults: A diagnostic approach, J Inherit Metab Dis 31(3) (2008), 308-318.

[24] O. Bonnot, H.H. Klunemann, F. Sedel, S. Tordjman, D. Cohen and M. Walterfang, Diagnostic and treatment implications of psychosis secondary to treatable metabolic disorders in adults: A systematic review, Orphanet J Rare Dis 9 (2014), 65.

[25] S. Chanprasert and F. Scaglia, Adult liver disorders caused by inborn errors of metabolism: Review and update, Mol Genet Metab 114(1) (2015), 1-10.

[26] A. Evangeliou, K. Papadopoulou-Legbelou, E. Daphnis, E. Ganotakis, I. Vavouranakis, H. Michailidou, A. HitoglouMakedou, P. Nicolaidou, R. Wevers and G. Varlamis, Cardiac manifestations of inborn errors of metabolism, Minerva Pediatr 59(3) (2007), 215-218.

[27] M.J. Okumura and M.E. Kleinhenz, Cystic Fibrosis Transitions of Care: Lessons Learned and Future Directions for Cystic Fibrosis, Clin Chest Med 37(1) (2016), 119-126.

[28] K.F. Downing, M.E. Oster and S.L. Farr, Preparing adolescents with heart problems for transition to adult care, 2009-2010 National Survey of Children with Special Health Care Needs. Congenit Heart Dis 12(4) (2017), 497-506.

[29] A. Judd, I.J. Collins, F. Parrott, T. Hill, S. Jose, D. Ford, H. Asad, D.M. Gibb and C. Sabin, Growing up with perinatal HIV: Changes in clinical outcomes before and after transfer to adult care in the UK, J Int AIDS Soc 20(Suppl 3) (2017), 21577. 
[30] M. Schwarz and U. Wendel, [Inborn errors of metabolism (IEM) in adults. A new challenge to internal medicine (Part 2)], Med Klin (Munich) 100(10) (2005), 624-635.

[31] S. Sirrs, C. Hollak, M. Merkel, A. Sechi, E. Glamuzina, M.C. Janssen, R. Lachmann, J. Langendonk, M. Scarpelli, T. Ben Omran and others, The Frequencies of Different Inborn Errors of Metabolism in Adult Metabolic Centres: Report from the SSIEM Adult Metabolic Physicians Group, JIMD Rep 27 (2016), 85-91.

[32] J. Reiss, Health care transition for emerging adults with chronic health conditions and disabilities, Pediatr Ann 41(10) (2012), 429-435.

[33] K.M. Stepien and C.J. Hendriksz, The principles of the transition process from paediatric to adult services in inborn errors of metabolism-own experience, Dev Period Med 19(4) (2015), 523-527.

[34] A.J. Brooks, P.J. Smith, R. Cohen, P. Collins, A. Douds, V. Forbes, D.R. Gaya, B.T. Johnston, P.J. McKiernan, C.D. Murray and others. UK guideline on transition of adolescent and young persons with chronic digestive diseases from paediatric to adult care, Gut 66(6) (2017), 988-1000.

[35] J. Perez-Lopez, L. Ceberio-Hualde, J.S. Garcia Morillo, J.M. Grau-Junyent, A. Hermida Ameijeiras, M. LopezRodriguez, M. Morales-Conejo, J.J. Nava Mateos, L.J. Aldamiz Echevarri Azuara, J. Campistol and others, [Transition process from paediatric to adult care in patients with inborn errors of metabolism. Consensus statement]. Med Clin (Barc) 147(11) (2016), 506.e1-506.e7.

[36] C. Tran, F. Barbey, N. Pitteloud, J. Philippe, I. Kern and L. Bonafe, [Inborn errors of metabolism: Transition from childhood to adulthood], Rev Med Suisse 11(462) (2015), 445-449.

[37] C.D. Bethell, D. Read and K. Brockwood, Using existing population-based data sets to measure the American Academy of Pediatrics definition of medical home for all children and children with special health care needs, Pediatrics 113(5 Suppl) (2004), 1529-1537.

[38] J.E. McDonagh, T.R. Southwood and K.L. Shaw, The impact of a coordinated transitional care programme on adolescents with juvenile idiopathic arthritis, Rheumatology (Oxford) 46(1) (2007), 161-168.

[39] J.A. Koos and A. Bassett, Genetics Home Reference: A Review, Med Ref Serv Q 37(3) (2018), $292-299$.

[40] R.A. Ortiz, S. Witte, A. Gouw, A. Sanfilippo, R. Tsai, D. Fumagalli, C. Yu, K. Lant, N. Lipitz, J. Shepphird and others. Engaging a Community for Rare Genetic Disease: Best Practices and Education From Individual Crowdfunding Campaigns, Interact J Med Res 7(1) (2018), e3.

[41] K. Wittmeier, C. Holland, K. Hobbs-Murison, E. Crawford, C. Beauchamp, B. Milne, M. Morris and R. Keijzer, Analysis of a parent-initiated social media campaign for Hirschsprung's disease, J Med Internet Res 16(12) (2014), e288.

[42] F. Bomba, C. Herrmann-Garitz, J. Schmidt, S. Schmidt and U. Thyen, An assessment of the experiences and needs of adolescents with chronic conditions in transitional care: A qualitative study to develop a patient education programme, Health Soc Care Community 25(2) (2017), 652-666.

[43] M. Lino, K. Kuczynski, N. Rodriguez and T. Schap, Expenditures on Children by Families, 2015. In: Agriculture USDo, editor 2017.

[44] X. Zhao, T.F. Page, A.R. Altszuler, W.E. Pelham 3rd, H. Kipp, E.M. Gnagy, S. Coxe, N.K. Schatz, B.M. Merrill, F.L. Macphee and others. Family Burden of Raising a Child with ADHD, J Abnorm Child Psychol 2019.

[45] Y. Mori, J. Downs, K. Wong, B. Anderson, A. Epstein and H. Leonard, Impacts of caring for a child with the CDKL5 disorder on parental wellbeing and family quality of life, Orphanet J Rare Dis 12(1) (2017), 16.

[46] C.L. Laurvick, M.E. Msall, S. Silburn, C. Bower, N. de Klerk and H. Leonard, Physical and mental health of mothers caring for a child with Rett syndrome, Pediatrics 118(4) (2006), e1152-64.

[47] J.C. Brehaut, D.E. Kohen, P. Raina, S.D. Walter, D.J. Russell, M. Swinton, M. O'Donnell and P. Rosenbaum, The health of primary caregivers of children with cerebral palsy: How does it compare with that of other Canadian caregivers? Pediatrics 114(2) (2004), e182-91.

[48] U. Thyen, K. Kuhlthau and J.M. Perrin, Employment, child care, and mental health of mothers caring for children assisted by technology, Pediatrics 103(6 Pt 1) (1999), 1235-1242.

[49] M. Schlander and M. Beck, Expensive drugs for rare disorders: To treat or not to treat? The case of enzyme replacement therapy for mucopolysaccharidosis VI, Curr Med Res Opin 25(5) (2009), 1285-1293. 